\title{
Carrossel
}

sonoro

Sinfonia na cidade
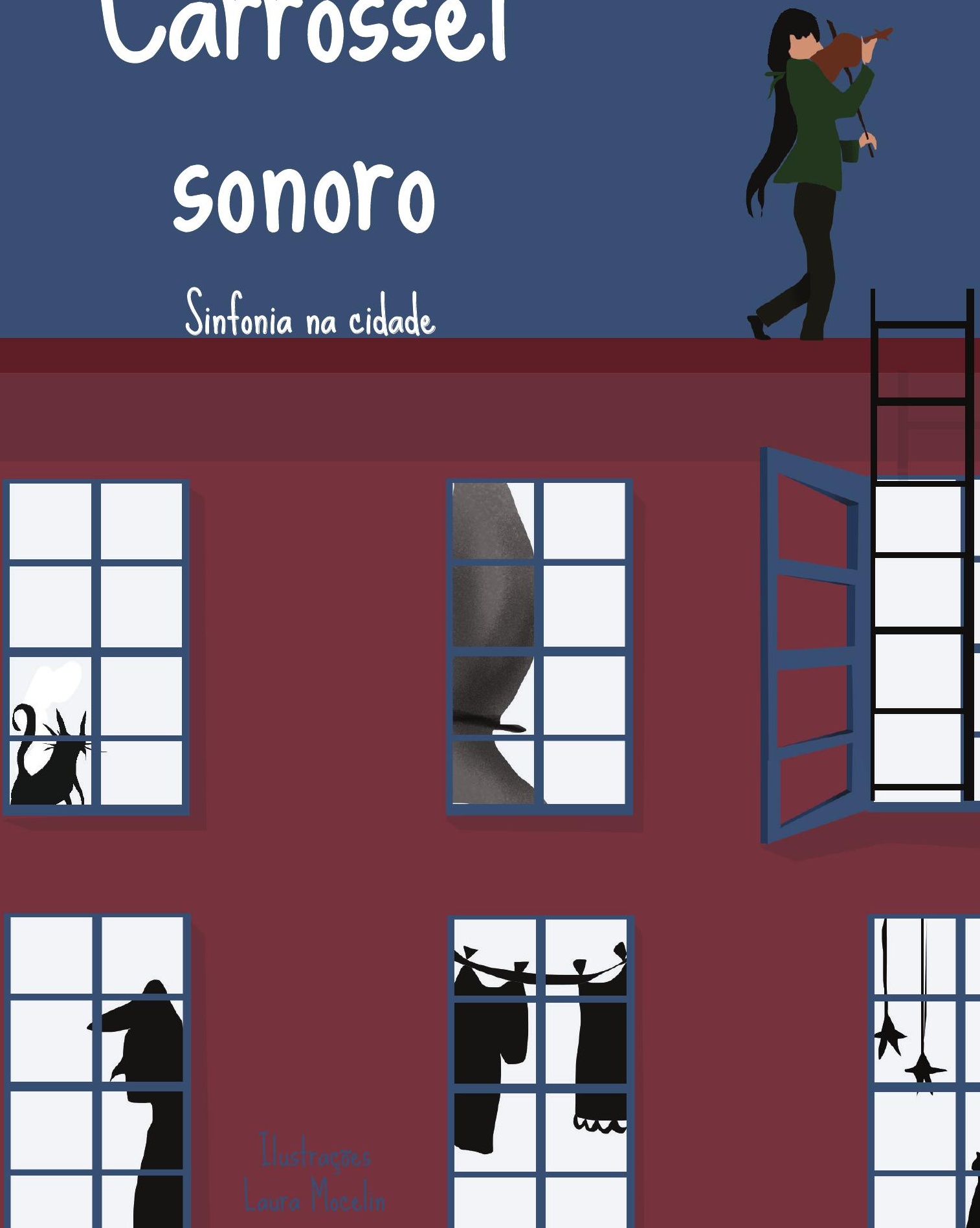


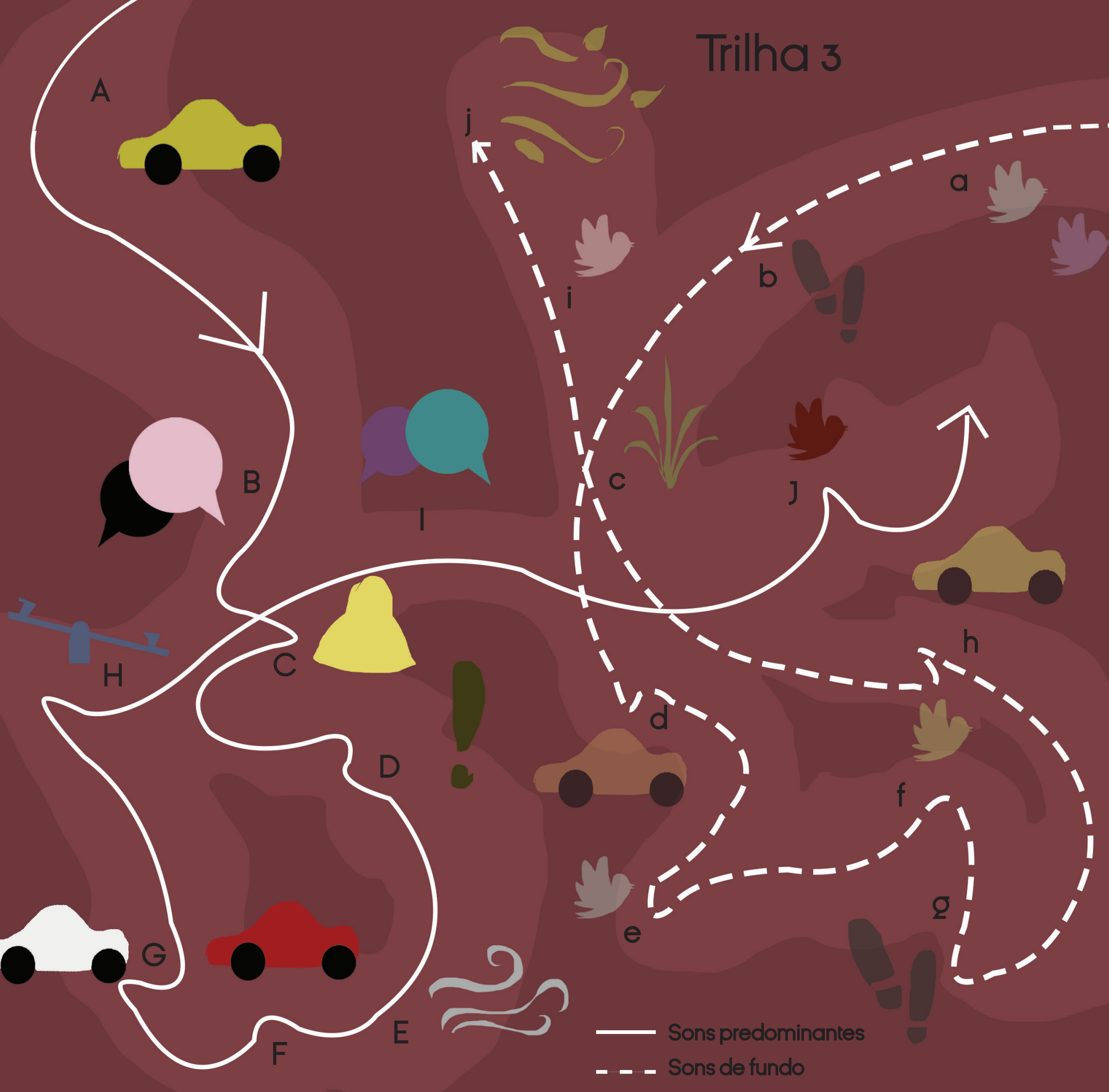




\title{
Sinfonia na Cidade
}

\section{Carrossel sonoro}

1Ediçāo

\author{
Erechim
}

Marcela Álvares Maciel

2019 


\section{FICHA CATALOGRÁFICA}

Dados Internacionais de Catalogação na Publicação (CIP)

(Even3 Publicações, PE, Brasil)

\section{CA319 Carrossel sonoro / Sinfonia na cidade. - 1. ed. - Recife:}

Even3 Publicações, 2019.

1 livro digital ; 32 p. : il. - (Passeios Sonoros)

Organizador: Marcela Alvares Maciel

Ilustrador: Laura Mocelin

DOI: $10.29327 / 510172$

ISBN: 978-85-5722-380-6

1. Urbanismo e Paisagismo. 2. Paisagem e Arte Sonora. 3. Patrimônio Imaterial Sonoro. I. Sinfonia da Cidade. II. Título. III. Série.

CDD 710

CDU 711

Copyright ${ }^{\circ} 2019$ - Todos os direitos reservados à: Marcela Álvares Maciel 
Qual o som da cidade? A complexidade da questāo do ruído nas cidades nāo pode ser reduzida ao estudo dos níveis de pressāo sonora, devendo incluir a percepçāo da qualidade da paisagem sonora. A compreensāo do valor patrimonial dos sons no contexto urbano é sustentada pelo conceito de territórios sonoros, que pode ser definido como a delimitaçāo de um espaço a partir dos sons que the sāo peculiares, isto é, onde as sonoridades cotidianas constituem-se como formas de expressāo de um espaço vivido em comum; onde circulam emoçōes e simbolismos; onde se inscreve a memória coletiva; onde o tempo condensa-se no espaco. Assim, este poema se realiza a partir das diretrizes da Convençāo para a Salvaguarda do Patrimônio Cultural Imaterial para a registro e catalogaçāo científica do patrimônio cultural imaterial sonoro de uma localidade.

Para tanto, utiliza-se de métodos de etnografia sonora para a construçāo de arquivos documentais das paisagens sonoras para possibilitar sua preservaçāo, estudo e posterior difusāo. Lugares sonoros significativos identificados pela comunidade de Erechim em instalaçāo artística itinerante "Sons e Memórias" foram organizados em trilhas para passeios sonoros a partir da avaliaçāo da potencialidade dos ambientes sonoros como objeto de gravaçāo, simulando-se previamente o melhor percurso e o tempo, incluindo as pausas que visavam destacar um ou outro conjunto sonoro.
Foram definidas trilhas com até 10 pontos de escuta de 5 minutos cada, caracterizando uma diversidade de paisagens sonoras cotidianas, tais como feiras e mercados; pracas e parques; agroindustrial; santuários; transportes; rural e domésticas. Para cada trilha, foram realizados quatro passeios sonoros, em grupo de até sete participantes, sendo cinco destinados aos testes subjetivos e outros dois responsáveis por registros fotográficos dos pontos de escuta e gravaçōes de áudios das paisagens sonoras.

Como resultados da coleta de dados, temos a realizaçāo de cerca de 600 testes subjetivos de preferência sonora e cerca de 10 horas de gravaçōes de paisagens sonoras e suas respectivas mediç̄oes de níveis de pressāo sonora.

A questāo aberta dos testes subjetivos relativa a pensamentos e sentimentos do sujeito após a escuta da paisagem sonora foi sintetizada para cada lugar sonoro em nuvem de palavras e posterior construçāo de poema sonoro a partir de técnicas de narrativa compartilhada. Cada lugar sonoro foi representado por um conjunto de versos que representam os sentimentos dos sujeitos relativos a paisagem sonora avaliada. O agrupamento de todos os versos obtidos para um passeio sonoro completo compōe o poema intitulado "Carrossel sonoro". 


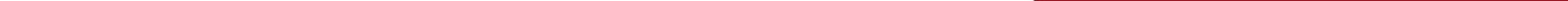




$$
\text { 罗 }
$$




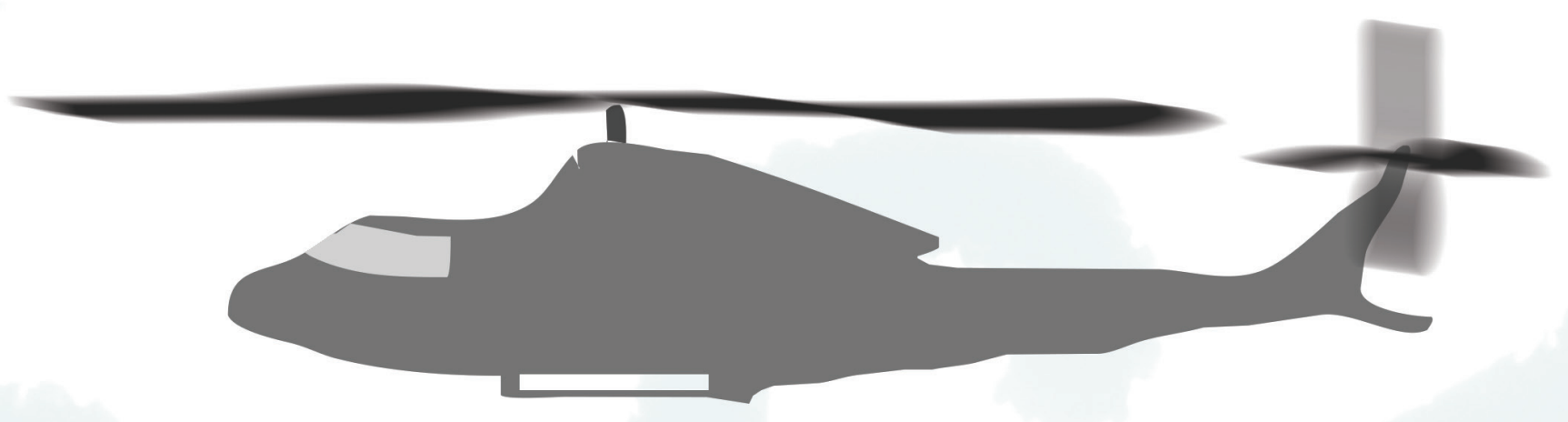

1


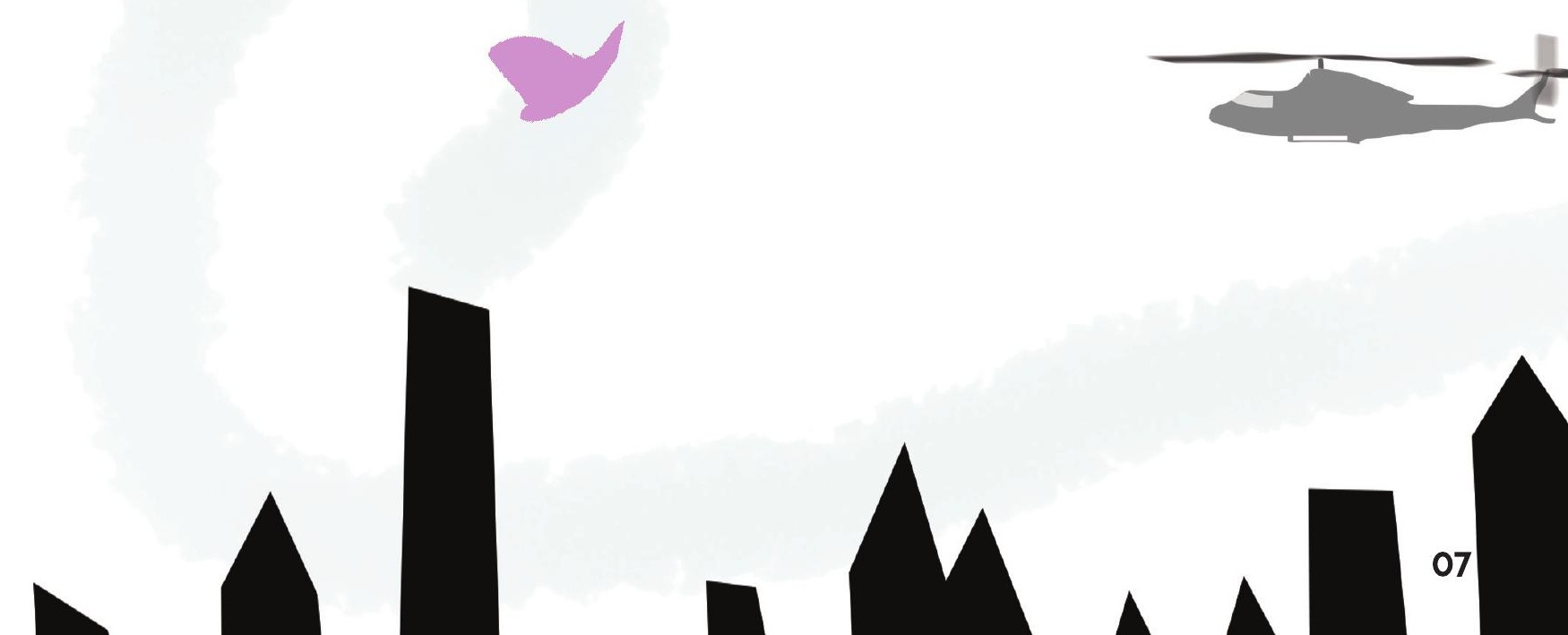


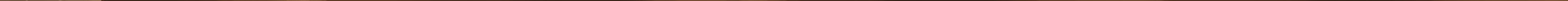


Conversas, passos, balanços e gangorras...

Os sons da praça sāo como a natureza

Em meio a cidade urbana movimentada:

Irritaçāo com o barulho de veículos

Contraponto com a calmaria da praça

Num lugar que gostaria de voltar.
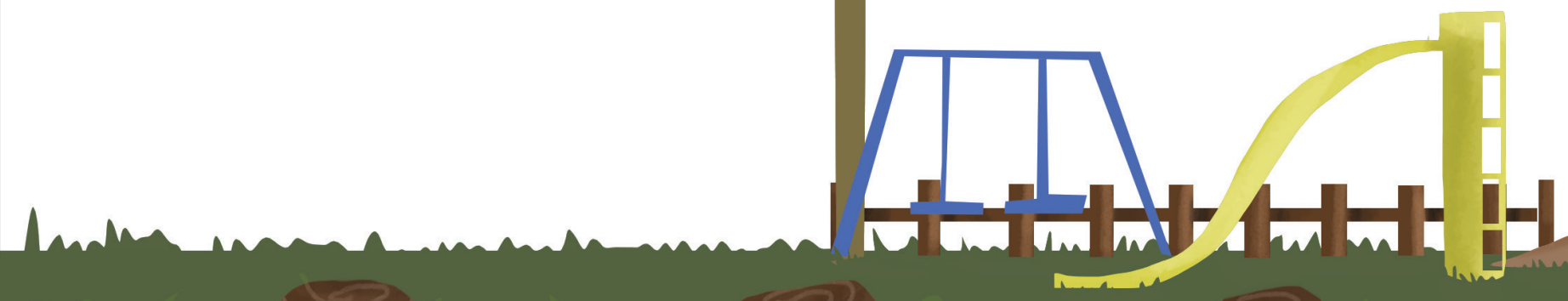
Ambiente confuso ... desconfortável ...

Carrossel de ruídos de carros e motos

Escutem, os sons de água deixaram o ambiente interessante!

Local agradável para curtir família e amigos.

Mas nāo ficaria por muito tempo aqui... 
Me senti um pouco atordoado ...

Dificil de pensar, irritante!

O som reflete o local:

Criancas gritando e carros acelerando Local de passagem, quero sair logo daqui! 


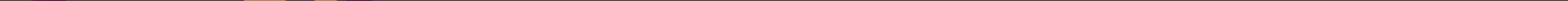


Lugar tranqüilo e relaxante Aconchegante para permanência Sons do vento, árvores, pássaros e cāes: Imersivo pelos sons naturais.
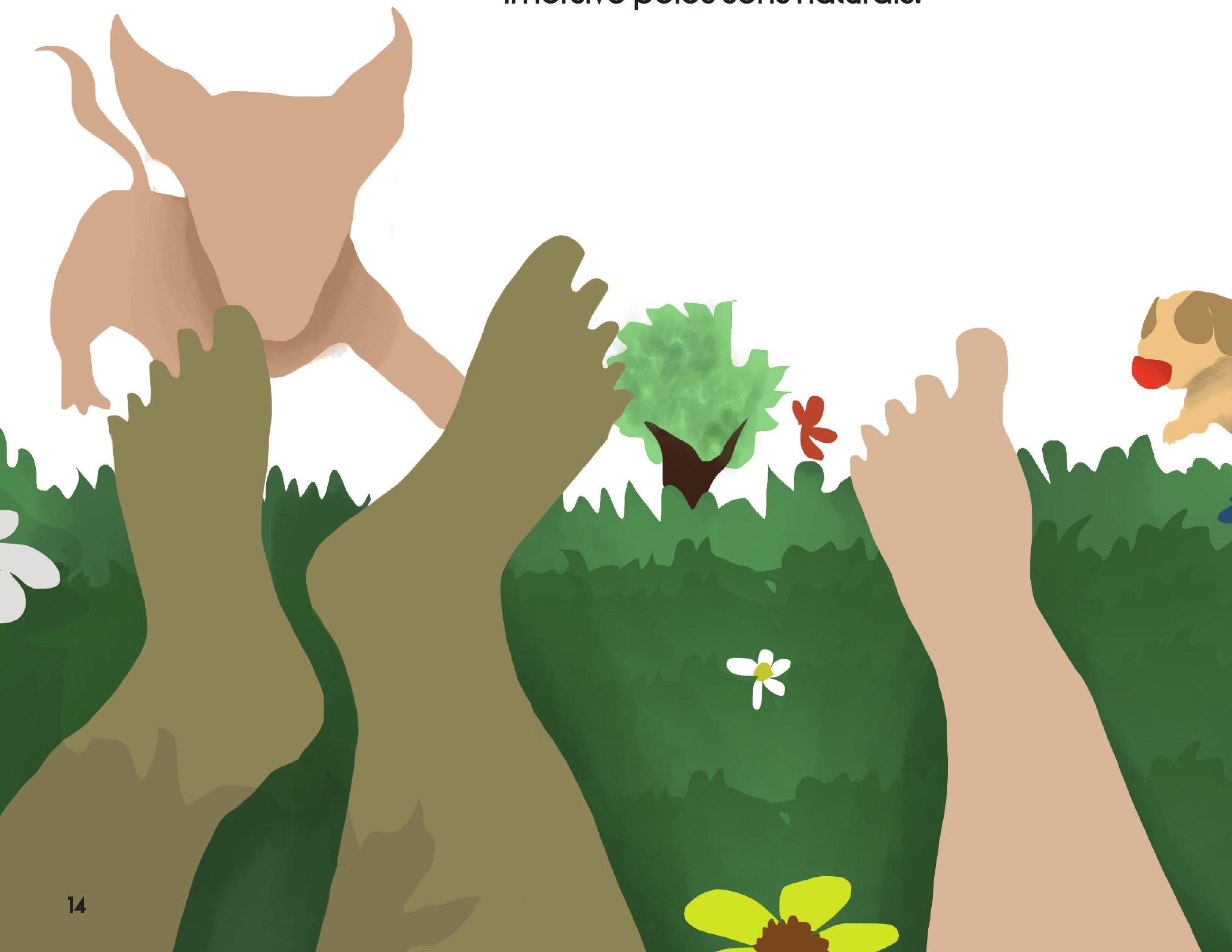
Lugar cercado de árvores e tráfego

Totalmente ruidoso

Sons de pássaros ao fundo.

O local perdeu seus sons agradáveis...

Me senti triste... 


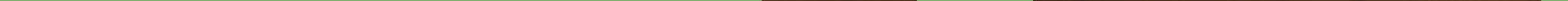




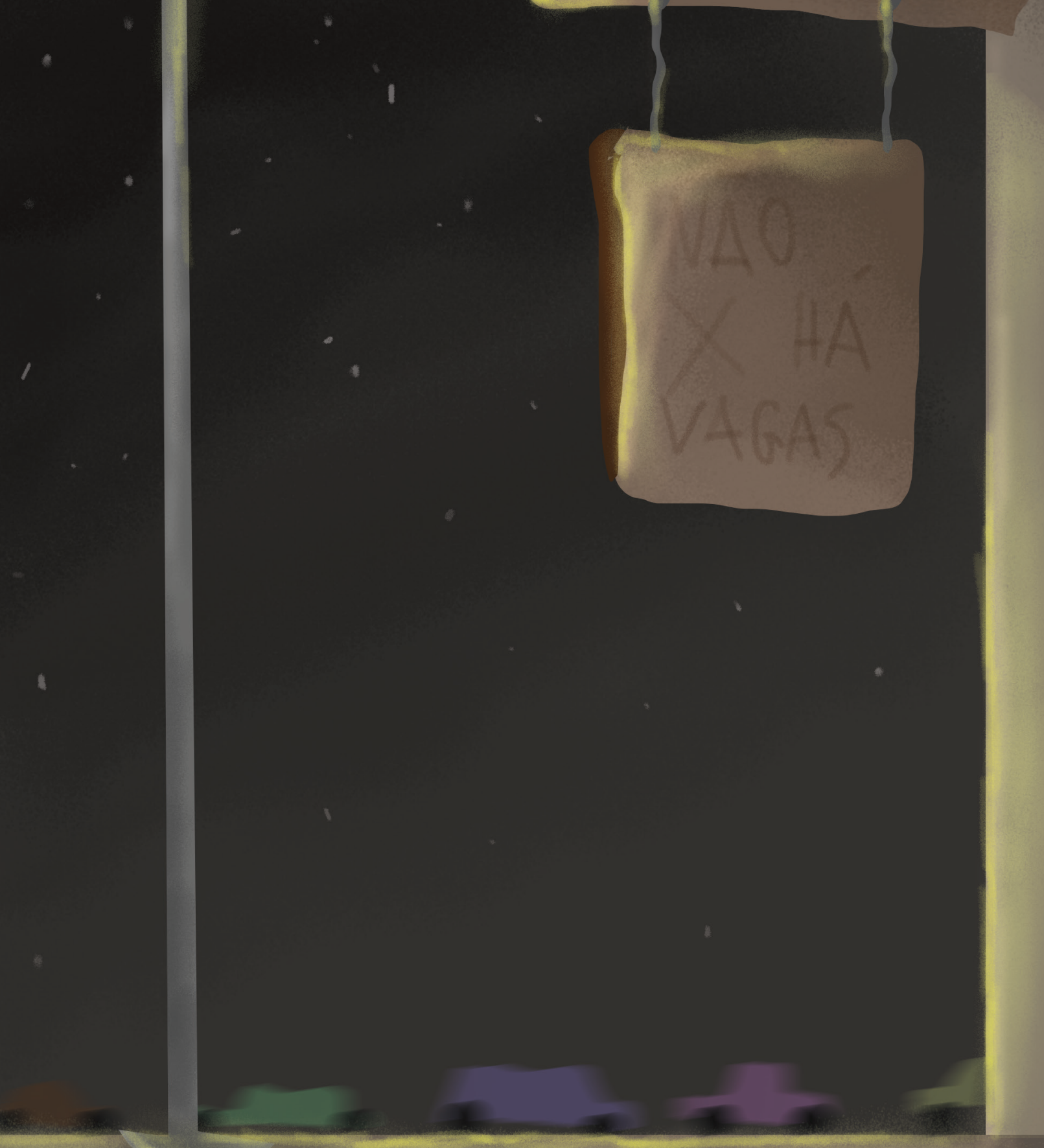




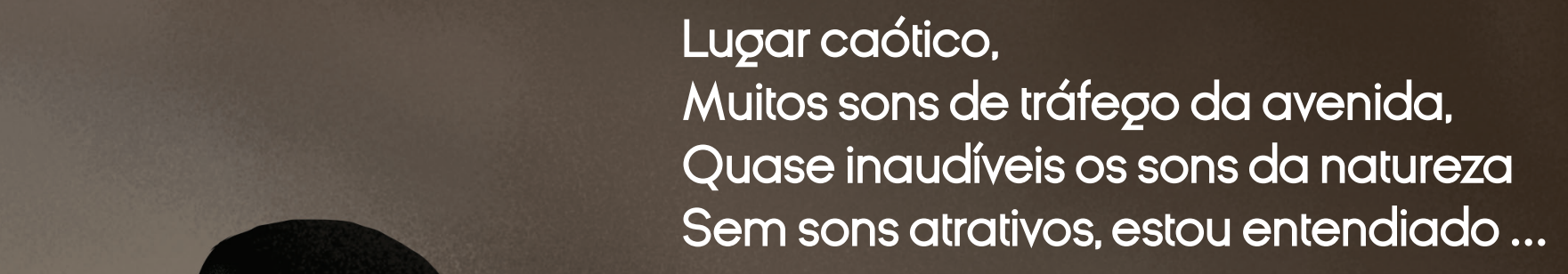


Me sinto bem nesse lugar!

Sons contínuos do balanço.

Poucos sons da fauna,

Carros circulam cal-ma-men-te!

Recanto de paz! 


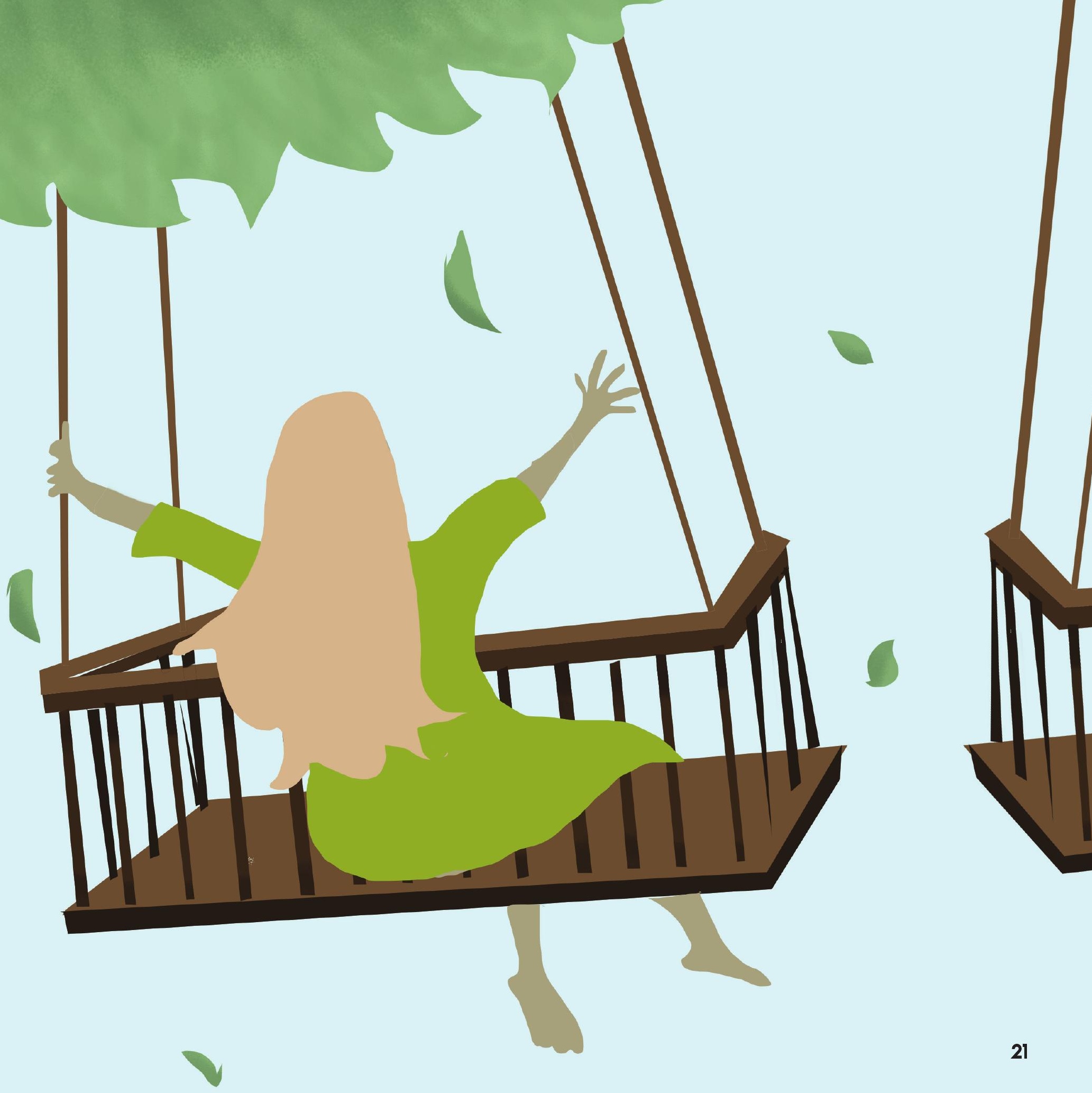


Paz, suavidade, leveza:

Na ausência dos carros

Sons humanos se destacam,

Pássaros trazem sensaçāo boa!

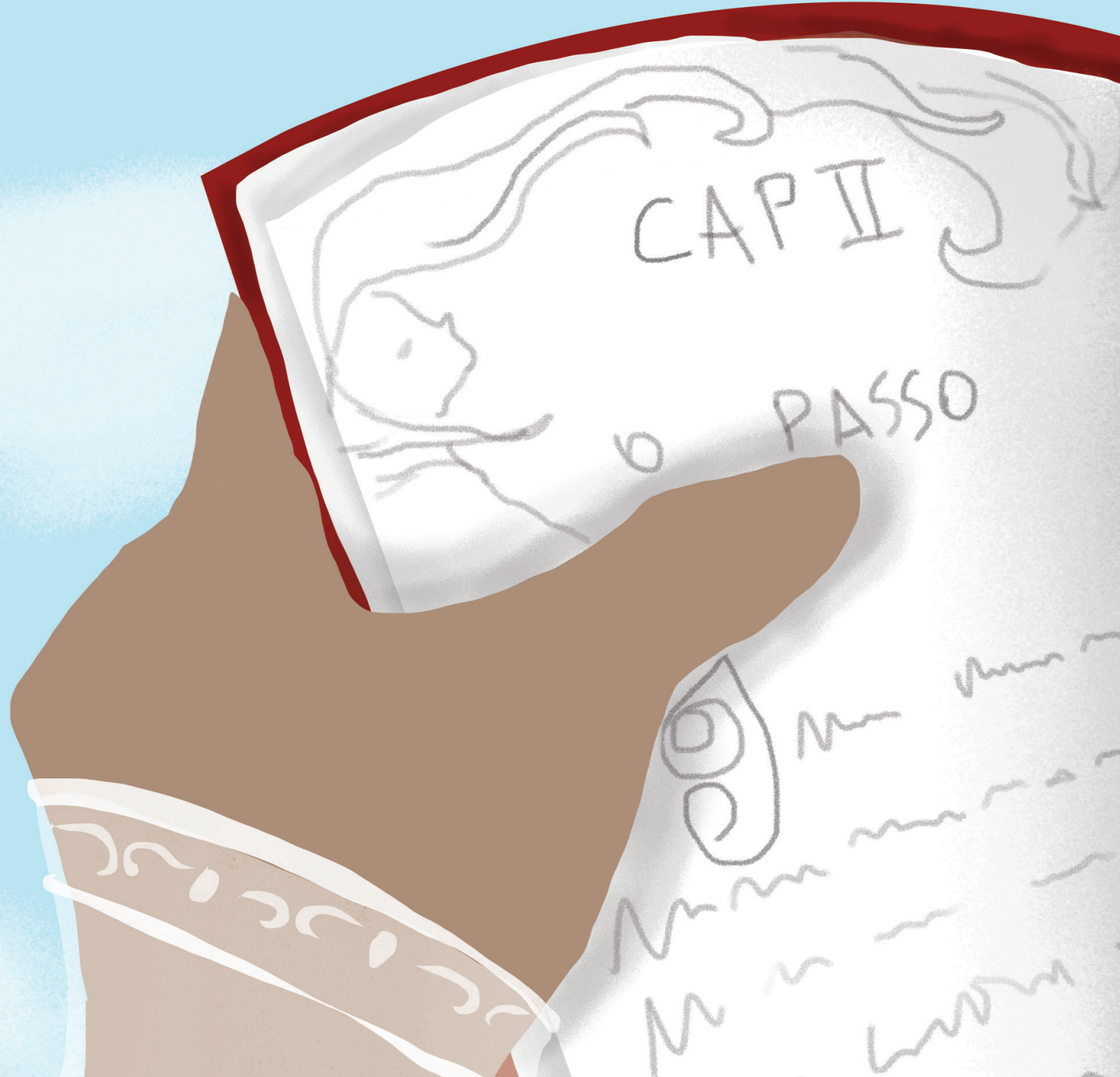




$$
V^{*}
$$




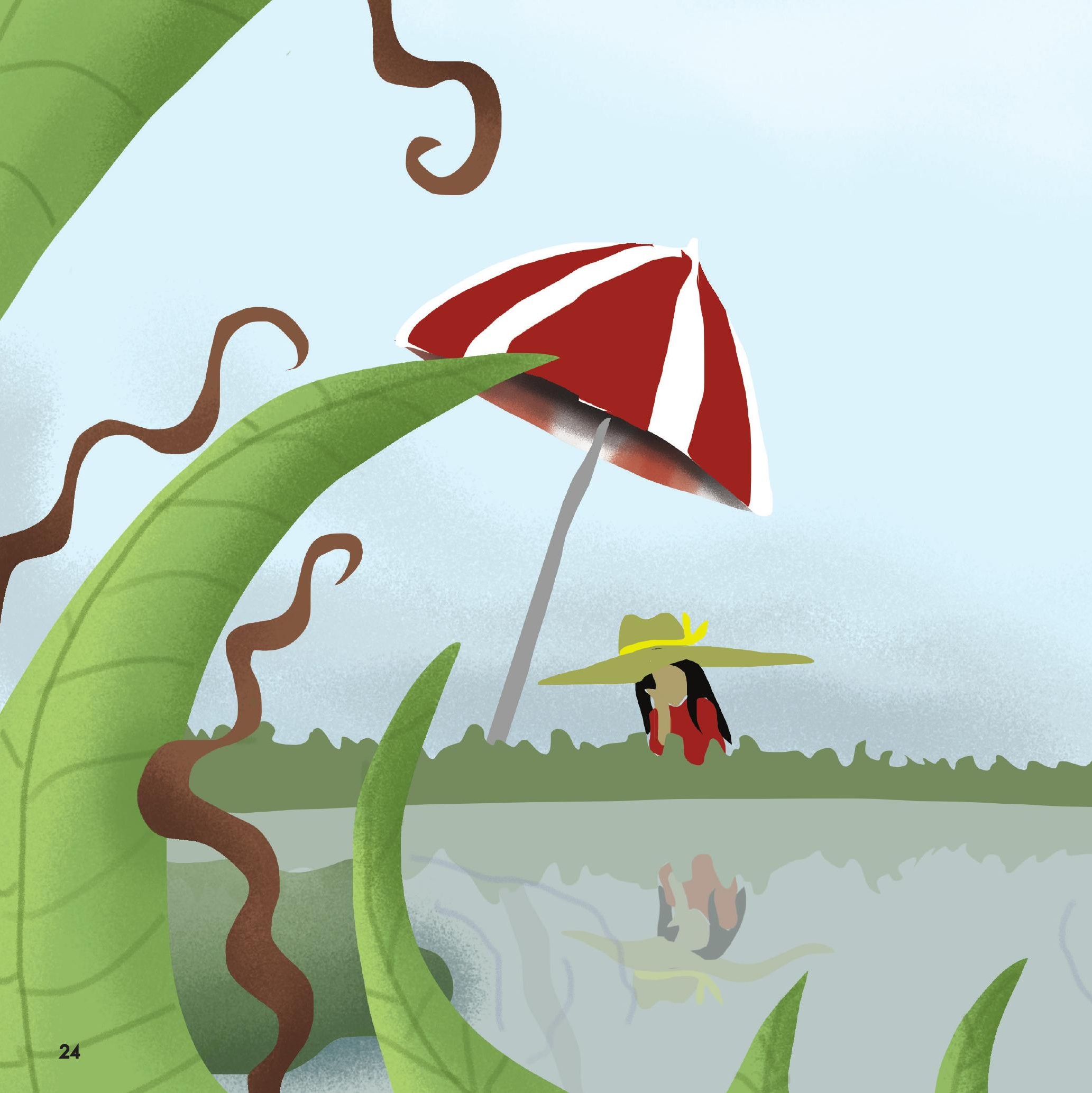




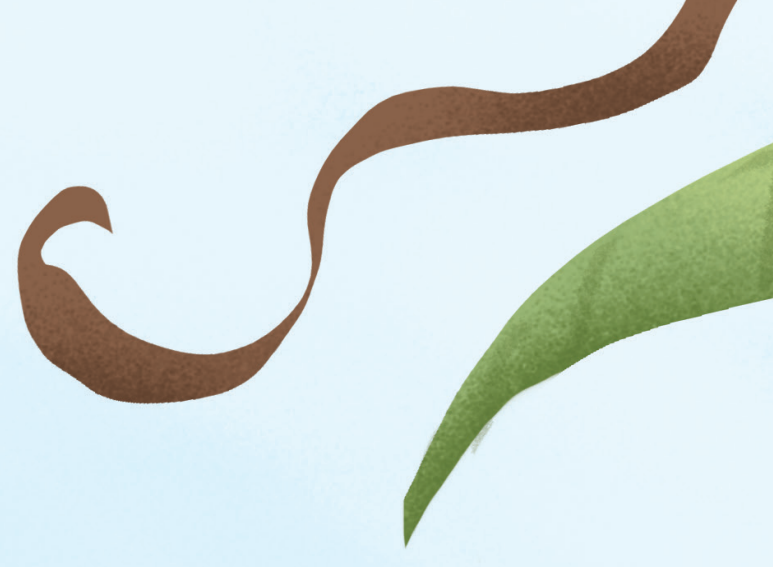

Paz, calma, tranquilidade:

Sons naturais se destacam dos tecnológicos:

Pouco tráfego, pássaros e animais

Sons pacatos alternados ...

Com sons animais surpreendentes!

Ambiente sonoro diferenciado da cidade! 


\section{AUTORES}

Alice Olczevski

Alexandra Cristina Bet

Aline Maia da Silva

Amanda Dal Castel

André Schneider

Andressa Araujo

Beatriz Martins

Bruna Karlin Martinazzo

Cintia Soares

Daniela Javornik Barroso

Danieli Herpich

Danielli Mezzalira

Elis Drieli Frantz

Eloá Ferreira do Carmo

Emily Simionato

Gabriela de Quadros

Ingrid Oliveira

Jeanderson Szymanski

Joāo Antônio Ziviezzikoski
Juliana Reis

Júlio César Puhl

Kamila Gilioli

Lisiane de Rocco

Luan Vieira

Luiz Eduardo Minks

Maiara Marafon

Mariana de Aguiar

Mariane Azevedo

Marielen Finger

Marvin Rojeski

Natália Eggers

Pedro Silva

Rafaela Bosqueira

Sabrina Schmitz

Talita Casagranda

Yassanan Macioroski

Yuri Zanatta
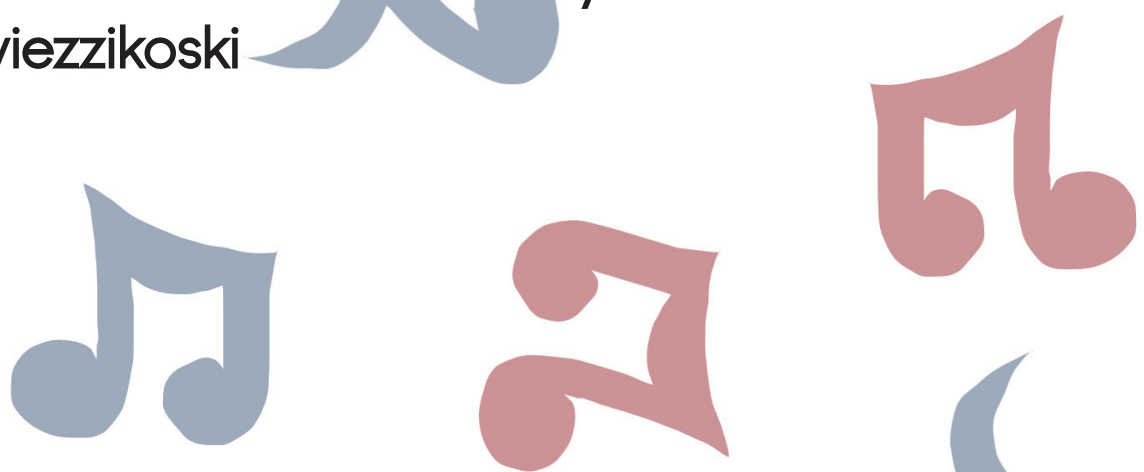


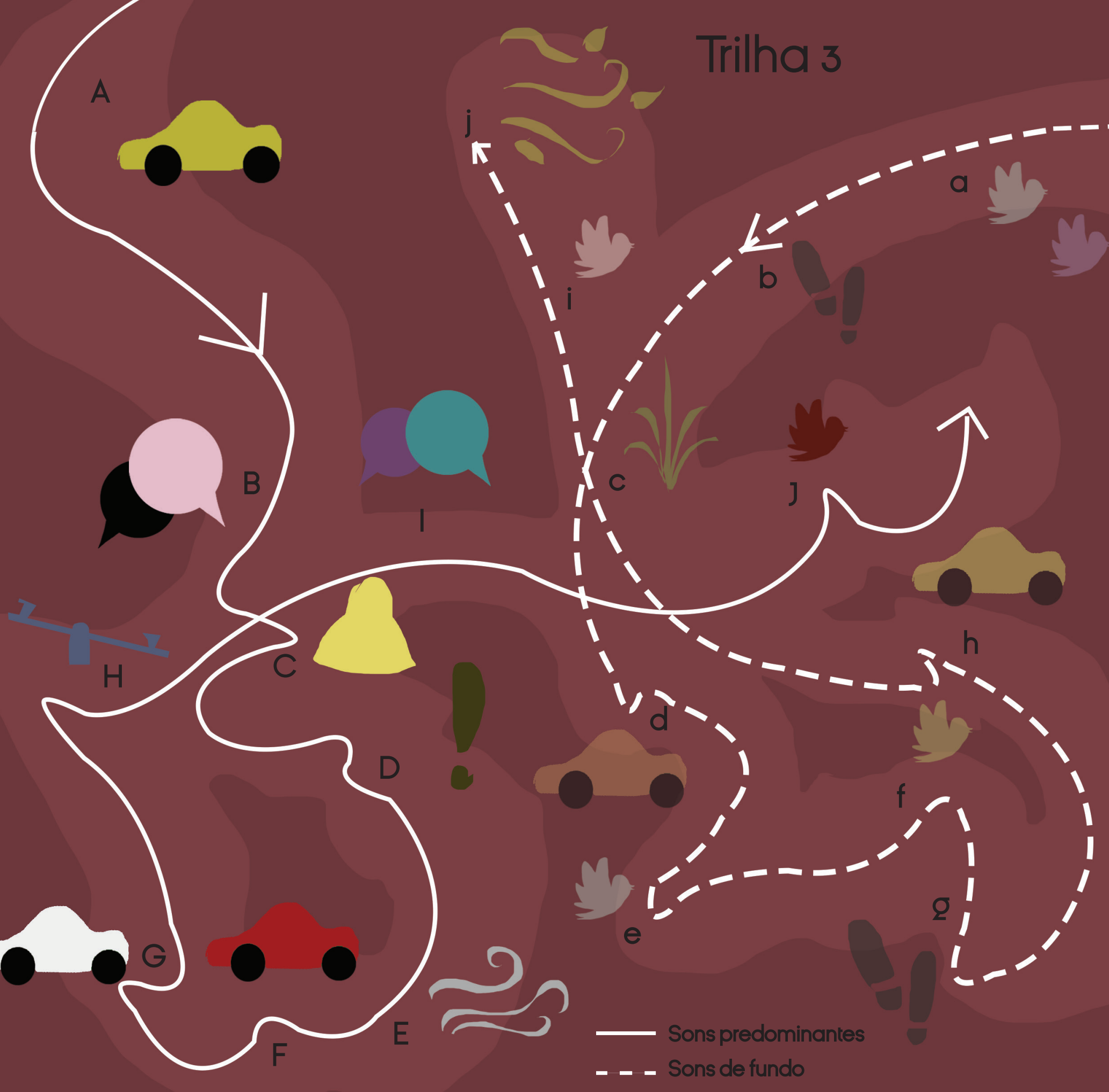


Existia um silêncio em meio ao caos.

Aos poucos as percepçrés cotidianas mudam, reviram, retorcem, se refazem. Tudo é transformação. "Carrossel sonoro revive um cotidiano que não percebemos mas que todos os dias nos faz diferentes.
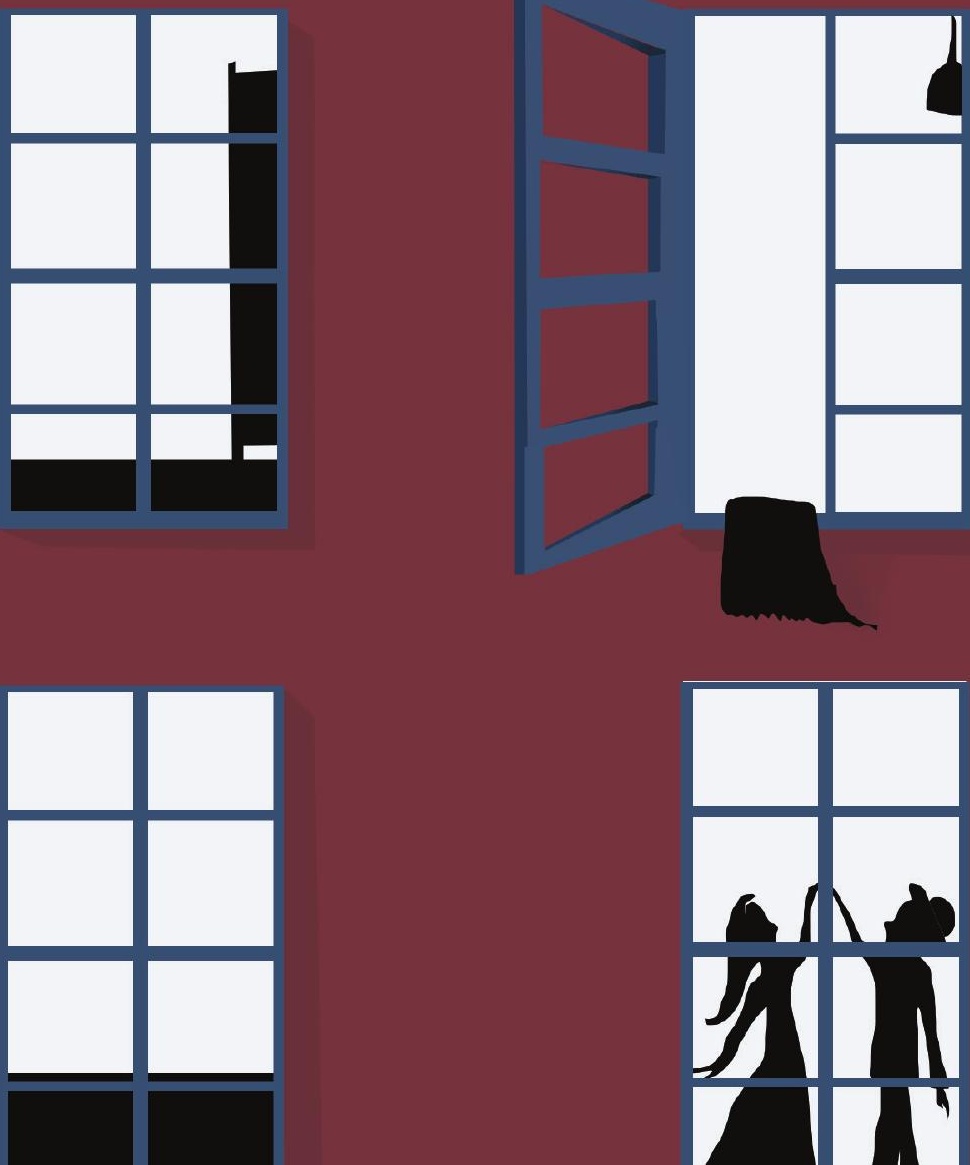